\title{
Microgravity vertical gradient measurement in the site of VIRGO interferometric antenna (Pisa plain, Italy)
}

\author{
Paolo Stefanelli $\left({ }^{1}\right)$, Cosmo Carmisciano $\left({ }^{1}\right)$, Fabio Caratori Tontini $\left({ }^{1}\right)$, Luca Cocchi $\left({ }^{1}\right)$, \\ Nicolò Beverini $\left({ }^{2}\right)$, Francesco Fidecaro $\left({ }^{2}\right)$ and Davide Embriaco $\left({ }^{1}\right)$ \\ (') Istituto Nazionale di Geofisica e Vulcanologia, Fezzano di Portovenere, La Spezia, Italy \\ $\left.{ }^{2}{ }^{2}\right)$ Dipartimento di Fisica, Università degli Studi di Pisa, Italy
}

\begin{abstract}
The site of the European Gravitational Observatory (EGO) located in the countryside near Pisa (Tuscany, Italy) was investigated by a microgravity vertical gradient (MVG) survey. The EGO site houses the VIRGO interferometric antenna for gravitational waves detection. The microgravity survey aims to highlight the gravity anomalies of high-frequency related to more superficial geological sources to obtain a detailed model of the lithologic setting of the VIRGO site, this will allow an estimate of the noise induced by seismic waves and by Newtonian interference. This paper presents the results of the gradiometric survey of 2006 in the area of the interferometric antenna. MVG measurements allow us to enhance the high frequency signal strongly associated with the shallow structures. The gradient gravity map shows a main negative pattern that seems related to the trending of the high density layer of gravel revealed in geotechnical drillings executed along the orthogonal arms during the construction of the VIRGO complex. Calibrating the relationship between the vertical gradient and the depth of the gravel interface we have computed a model of gravity gradient for the whole VIRGO site, defining the 3D distribution of the top surface of this layer. The latter shows a NE-SW negative pattern that may represent a palaeobed alluvial of the Serchio from the Bientina River system.
\end{abstract}

Key words Microgravity vertical gradient - near surface geology - gravity modeling.

\section{Introduction}

The VIRGO detector for gravitational waves consists mainly of a Michelson laser interferometer made of two orthogonal arms each being 3 kilometres long (Caron et al. 1997). Multiple reflections between mirrors located at the extremities of each arm extend the effective optical length of each arm up to 90

Mailing address: Dr. Paolo Stefanelli, Istituto Nazionale di Geofisica e Vulcanologia, via Pezzino Basso 2, 19025 Fezzano di Portovenere (SP), Italy; tel.: +39 0187 794400; fax: +390187 766400; e-mail:stefanelli@ingv.it $\mathrm{km}$. VIRGO is located within the site of consortium EGO, European Gravitational Observatory.

The high sensitivity of VIRGO requires a careful analysis of the small noise sources. In order to evaluate the external influences from environmental/anthropic disturbances, VIRGO is continuously monitored by several environmental sensors, like seismometers, microphones and electromagnetic probes. Considering the working frequency of the interferometer, the main noise sources may be divided into three groups: thermal, seismic and Newtonian. The latter group, which is linked to the density fluctuations within the crust that may generate the variation of the earth's gravitational field, is particularly insidious. As a matter of fact, each mirror of the VIRGO interferometer is isolated from seismic noise by a 10 
meters high, a very effective elaborate system of compound pendulums, but this filter is not effective for the Newtonian noise produced by longitudinal seismic perturbations.

A thorough knowledge of the geological setting near the antenna is very required for the assessment of these noise sources, particularly for the possible presence of local seismic amplifiers related to different composition and disposition of the layers.

In 2006, the INGV performed an MVG survey to investigate the geological setting at the VIRGO site. The main goal of this survey was to detect the trend of shallow layers of Holocene alluvial deposits. The sub-surface density variations related to different mineralogical composition of the rocks can be evidenced by changes induced in the local gravitational field. As these local variations are very small and mainly attributed to high frequency contribution of the gravity field, highly accurate gravimetric instrumentation and gravity gradient measurement techniques are particularly suitable. The study of the gravity gradient leads us to empha- size the shallow gravity sources with a strong decrease of the noise (Thyssen-Bornemisza and Stackler, 1956; Kumagai et al., 1960; Marson and Klingele, 1993). The gradient gravity measurements record the high frequency signal component associated with the shallow lateral density variations more clearly than the standard gravity measurements; gradiometer signal decreases with the cube of the distance from the source (Telford et al., 1990) while the gravity field decreases with the square of the distance.

Fajklewicz (1976) described the application of vertical gravity gradient measurements to the detection of tunnels and rock caverns beneath towns in Poland. Butler (1984) applied microgravity and gradient techniques to describe the shallow sub-surface cavities.

\section{Survey and data processing}

The survey network consisted of 59 stations located in an area of 4 by $4 \mathrm{~km}$ (fig. 1). The gravity data were sampled using a pair of

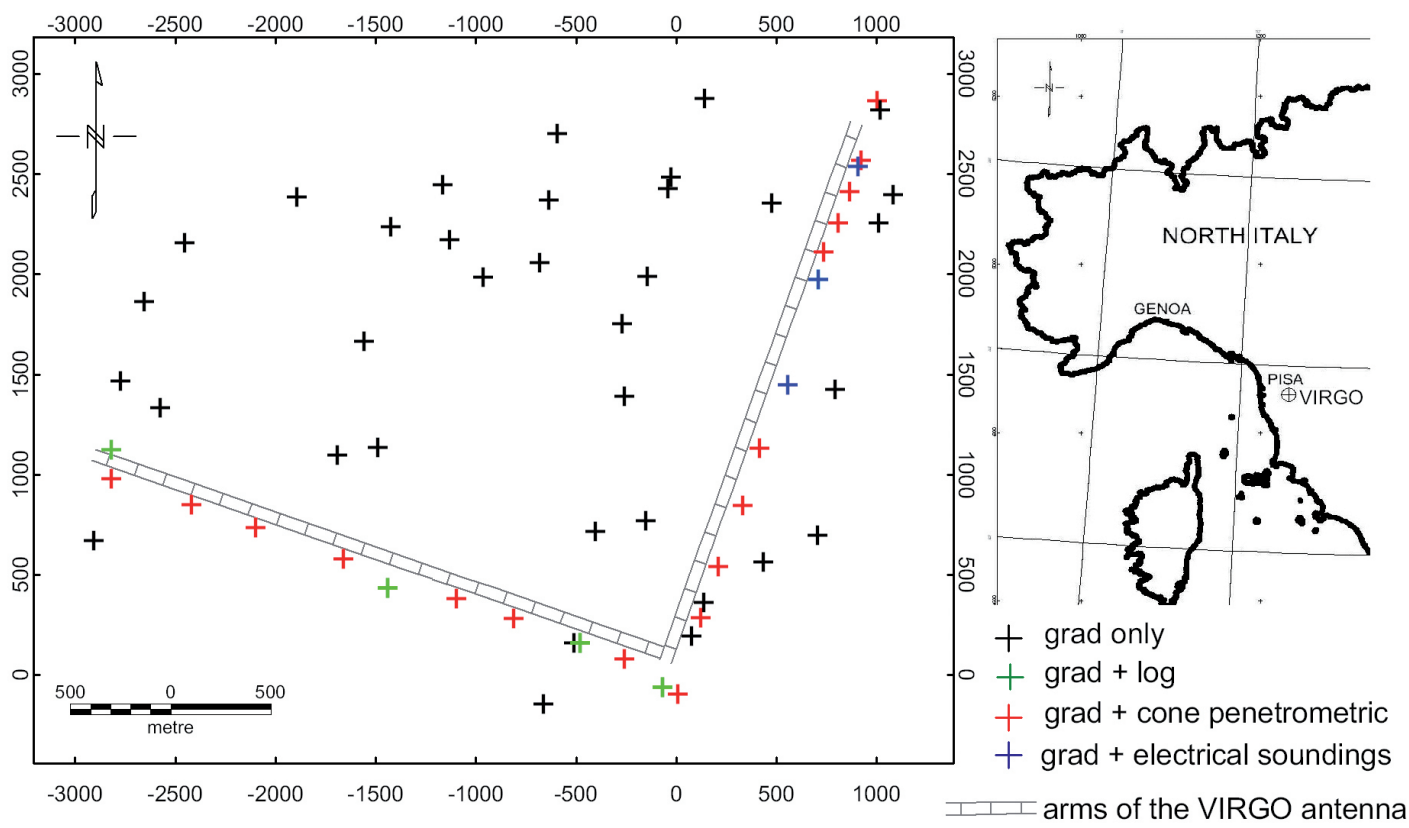

Fig. 1. Location of gravity stations; the network geometry is constrained by the presence of roads. 
LaCoste\&Romberg micro-gravimeters (Aliod model) equipped with a digital data acquisition system, GPS tracking and automatic tide corrections, with a nominal resolution of 1 $\mu \mathrm{Gal}\left(10 \mathrm{~nm} / \mathrm{s}^{2}\right)$. The geographic positions of the gravity stations were defined using the integrated position system of the gravimeter. In each station the value of gravity gradient was acquired using a portable tower frame characterized at the top by a moving plate useful to modify the height of the tower. The MVG measurement was achieved by two successive readings performed at the bottom and top of the tower frame. In this survey vertical offset was stated to $1.80 \mathrm{~m}$ as the best compromise between the operative requirement and the reading errors (Hunt et al., 2002; Hammer and Anzoleaga, 1975). The accuracy estimated for the MVG procedure is about 4-5 $\mu \mathrm{Gal} / \mathrm{m}$. The $g_{z z}$ component of the gradient tensor is approximated by the following formula:

$$
g_{z z}=\left(g_{b}-g_{1}\right) / h
$$

where $g_{b}$ and $g_{t}$ represent the bottom and top gravity values respectively and $h$ is the vertical distance between the two gravity measures. The elapsed time between the bottom and top reading at each station was about 5 minutes, which is short enough to make the error related to instrumental drift negligible (standard drift is $15-20 \mu \mathrm{Gal} /$ day).

The instrumental drift curve was also evaluated through a set of daily readings on a base station located near the survey area (see its location in fig. 1). It is noteworthy that the base station is an absolute gravity station obtained by a gravity transport from the near node of the Italian gravity network (Pisa).

The bottom readings were processed to estimate the standard gravity field and its related anomaly variations, by using the daily loops on the base station. The complete Bouguer correction (see the related map in fig. 2) was computed using the following steps: i) data correction by the recorded instrumental drift curve; ii) modified free-air correction adopting a normalized value of the computed local mean gradient of $324.2 \mu \mathrm{Gal} / \mathrm{m}$ instead of the normal free-air gradient value $(308.6 \mu \mathrm{Gal} / \mathrm{m})$ according to Ager and Liard (1982); iii) application of a topographic correction using a densely sampled Digital Elevation Model; we have chosen a $2.40 \mathrm{~g} / \mathrm{cm}^{3}$ value for the topographic density in the data reduction in accord with a previous study in this area by Cantini et al. (2001); iv) subtraction of a regional trend using a first order polynomial surface; v) Kriging-variogram interpolation with a grid cell size of $200 \mathrm{~m}$.

The map in fig. 3 shows the results of the gravity gradient acquisition. Comparing the Bouguer anomaly and the gradient value we can observe a strong correlation with a peak to peak gravity value and gravity gradient anomalies of $5.3 \mathrm{mGal}$ and $79 \mu \mathrm{Gal} / \mathrm{m}$ respectively. Both the maps give the same trend characterized by a positive anomaly near the origin arms of the antenna and a negative pattern area at the west and north portion of the studied area. At the origin of the antenna arms, the gravel layer is located in a shallow position near the topographic surface dipping westward and northward. The gravity gradient map highlights better than the Bouguer anomaly the negative anomaly pattern trending in the NE-SW direction.

\section{Geological setting}

The study area is located on the NeogeneQuaternary basin of the lower Arno River Valley. This sedimentary basin consists of a large tectonic depression that originated during the middle Miocene extensional phases as a result of the formation of the Northern Tyrrhenian Basin (Fanucci et al., 1987; Patacca et al.,1990; Carmignani et al., 1994). In this area the tectonics occurred as low-angle extension (Bartole et al., 1991) with a transition to high-angle extension during the upper Miocene. In this phase, the Mesozoic formations and the metamorphic Tuscan Unit, that made the actual core of the Pisa Mountains, were displaced for thousands of meters by high angle normal faults. The emplaced tectonic depression was subsequently filled by a Pliocenic marine succession and by PliocenePleistocenic fluvio-lacustrine succession. Holocenic deposits (recent alluvial deposits) are 


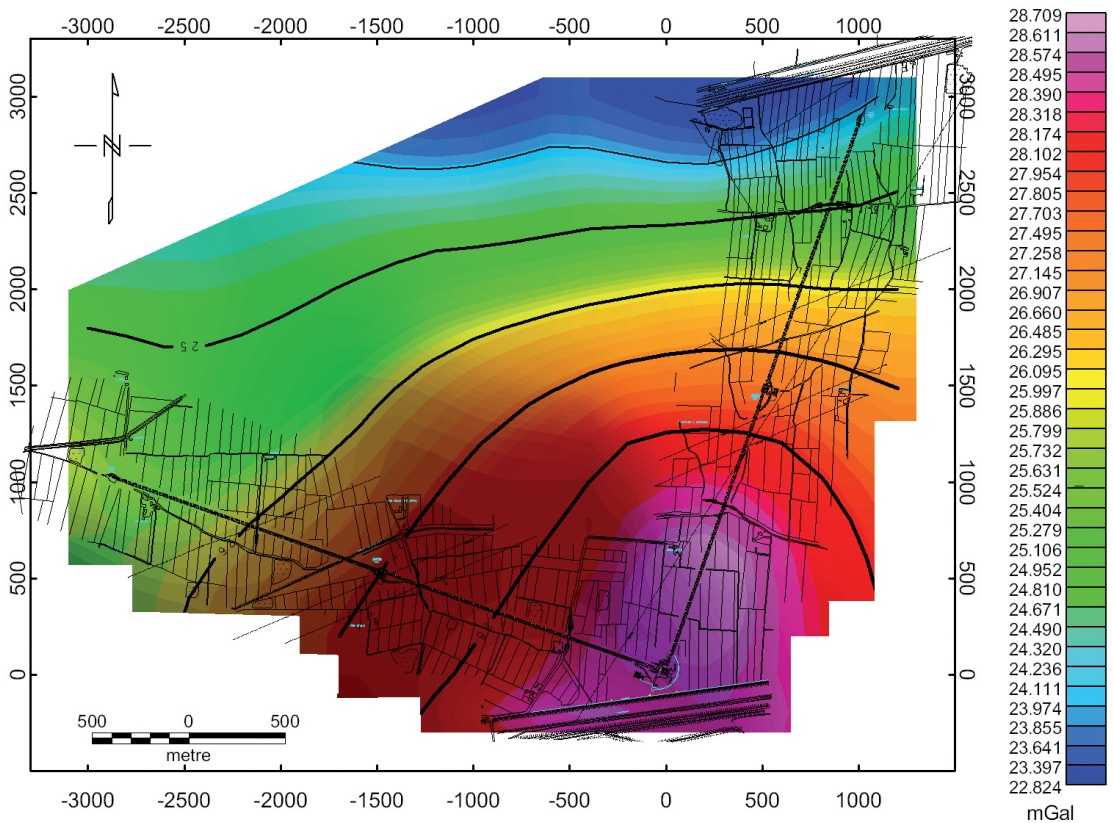

Fig. 2. Bouguer anomaly map (density $2.40 \mathrm{~g} / \mathrm{cm}^{3}$ ). The free-air correction was normalizing by the computed local mean gradient of $324.2 \mu \mathrm{Gal} / \mathrm{m}$. Contour interval at $1 \mathrm{mGal}$. The topographic information is shown only along the arms of the antenna.

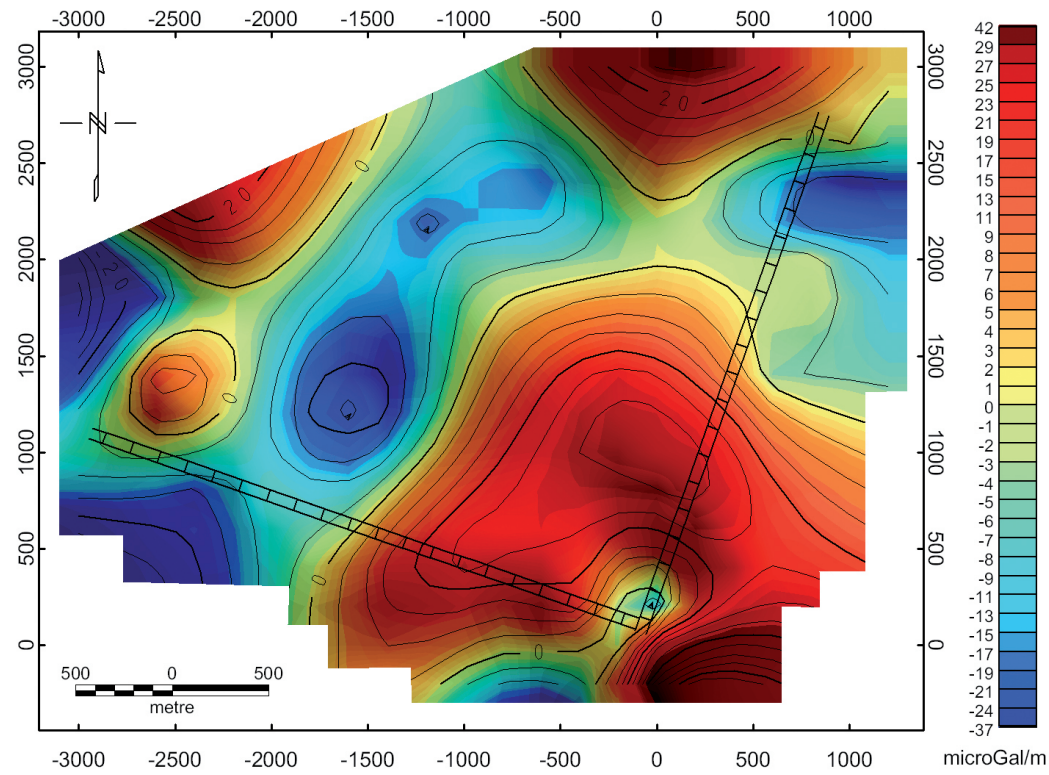

Fig. 3. Gravity gradient anomaly map. Contour interval at $5 \mu \mathrm{Gal} / \mathrm{m}$ with bolder lines at $20 \mu \mathrm{Gal} / \mathrm{m}$. 
commonly distinguished into four main layers; top to bottom: i) conglomerates of the Arno River and Serchio from Bientina River (Wurm II); ii) deep mud and clay fluvio-lacustrine; iii) sands; iv) shallow mud and clay fluvio-lacustrine.

Considering the geological setting of the VIRGO site, detailed geotechnical and geological data are available only for the sub-surface along the two arms of the antenna. Geological drillings were performed by GEOSER geological company during the building phase of the VIRGO complex, with a maximum depth of investigation of $70 \mathrm{~m}$, as well as a cone-penetrometric static test and a geo-electrical vertical sounding. Three main shallow layers, to the bottom from the top, were distinguished: gravel (conglomeratic deposit), sand and mud-clay. Figures $4 \mathrm{a}$ and $4 \mathrm{~b}$ show the top of the gravel layer surface (from the geotechnical data) along the two arms of the gravitational antenna and the respective gradient gravity signal profiles (from the MVG survey).

\section{Density of the alluvial deposits}

The conglomeratic deposits are made primary of coarse pebbles of limestone and secondary by sandstone, ophiolite and silica; this succession gives the maximum value of density: the latter ranging between $1.9-2.1 \mathrm{~g} / \mathrm{cm}^{3}$ as provided by the technical reports of applied geological works in the near areas. The mudclay and sand deposits have a density value of $1.5-1.8 \mathrm{~g} / \mathrm{cm}^{3}$ and $1.9-2.0 \mathrm{~g} / \mathrm{cm}^{3}$ respectively.

Recently Cantini et al. (2001) analyzed the tectonic setting of the Montecarlo basin which represents a region located northward of our survey area. In that paper the authors declared a density value of $2.25 \mathrm{~g} / \mathrm{cm}^{3}$ for the entire PlioPleistocene succession (marine and fluvio-lacustrine deposits).

The geotechnical study performed by GEOSER company, has detected the density of more clay-samples (by laboratory analysis) collected by drillings located near the origin and end of the north and west arms of the antenna. Nevertheless, some samples are very shallow (1-1.5 m depth), and other samples are related to a layer of inorganic clays (density range between $1.5 \mathrm{~g} / \mathrm{cm}^{3}$ and $1.8 \mathrm{~g} / \mathrm{cm}^{3}$ ) that lie under the conglomeratic deposit. We also utilized the available geological cross-sections along the two arms of the gravitational antenna (figs. 4a, 4b) to define the optimal density value of the alluvial deposits. We modeled the gravity Bouguer signal along the arms, where the geological setting is known, obtaining in this way a density value for each layer. The two gravity models are shown in figs. 5a, 5b. The density values provided by the $2.5 \mathrm{D}$ gravity model relative to the gravel $\left(2.1 \mathrm{~g} / \mathrm{cm}^{3}\right)$ and the clay $(1.5$ $\left.-1.6 \mathrm{~g} / \mathrm{cm}^{3}\right)$ are in agreement with the literature and collected values; on the contrary, the sands show a density of $1.7 \mathrm{~g} / \mathrm{cm}^{3}$, which is lower than the standard value: this difference is probably connected with aquifer conditions and/or the lateral discontinuity of this layer. The computed density values highlight that the shallow gravel layer represents the interface with the maximum contrast density respect to the other alluvial deposits.

\section{Gradient gravity modeling}

The relationship between the gravity gradient signal and the trending of the shallow gravel interface was analyzed using the detailed stratigraphic data. The contact between the conglomeratic deposit and the sands represents the main boundary density contrast, as previously highlighted by the $2.5 \mathrm{D}$ gravity models. We directly connected the variation of the gradient signal to the vertical displacement of this interface. Thus, we assigned at each acquired gravity gradient reading the corresponding value of the depth of the gravel-layer, based on the information coming from the geological drillings. The cross-points and relative error bars are plotted in fig. 6. The maximum errors arise especially from the uncertainty in identifying the top of the gravel when using the data related to cone penetrometric static tests. The best fit is given by a regression line having the coefficient (slope) equal to $-0.33 \mathrm{~m}^{2} / \mu \mathrm{Gal}$, constant (Y intercept) equal to $150.9 \mathrm{~m}$ and a standard deviation slope equal to $0.089 \mathrm{~m}^{2} / \mu \mathrm{Gal}$. The best fit operation 

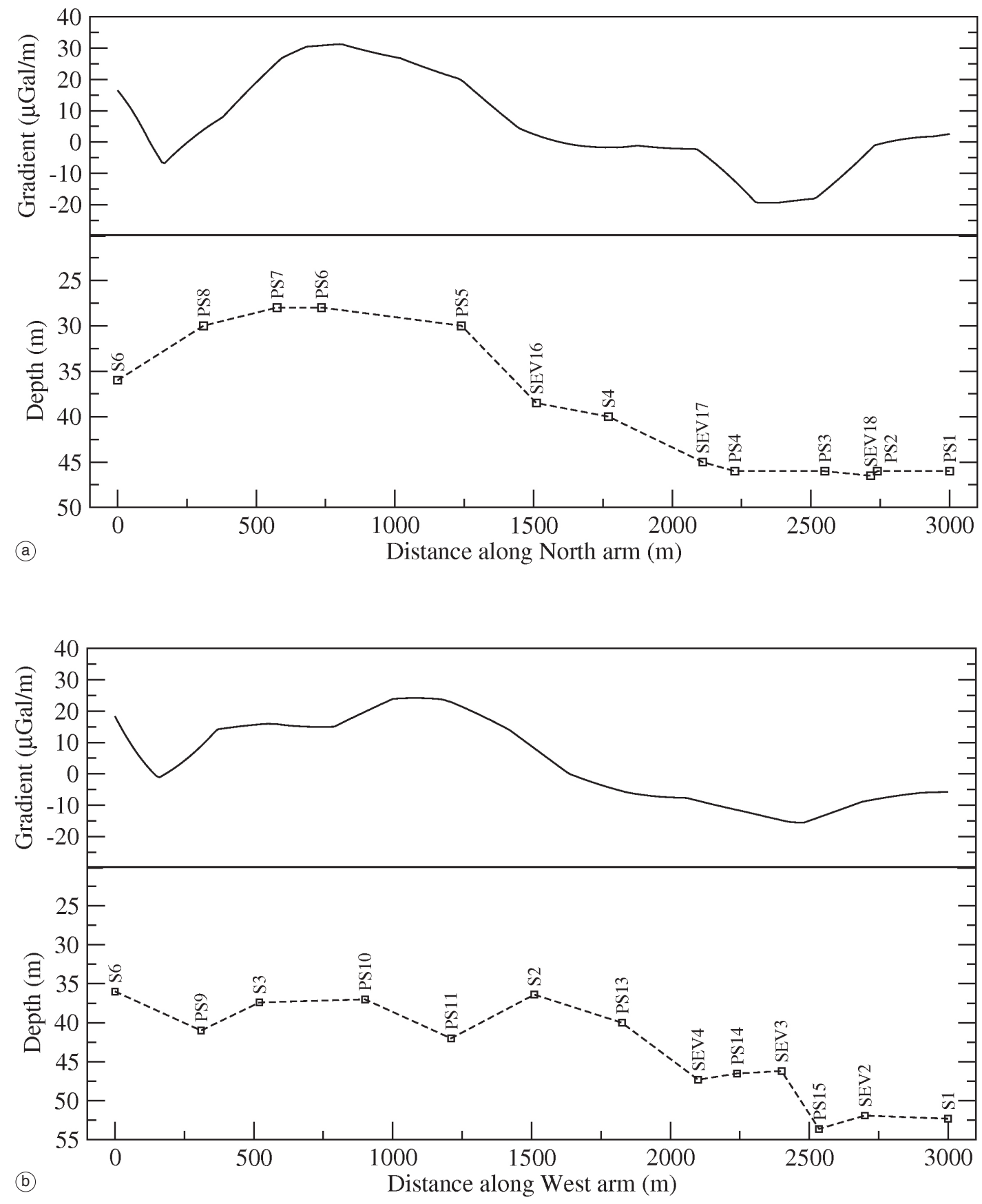

Fig. 4a,b. Gradient signal (up) and depth of gravel layer (down) along the two arms of the antenna (a: North; b: West). Geologic data from: well log (S), cone penetrometric static (PS) and vertical electrical soundings $(\mathrm{SEV})$. The good agreement between the gradient signal and the trend of conglomeratic layer are shown. 

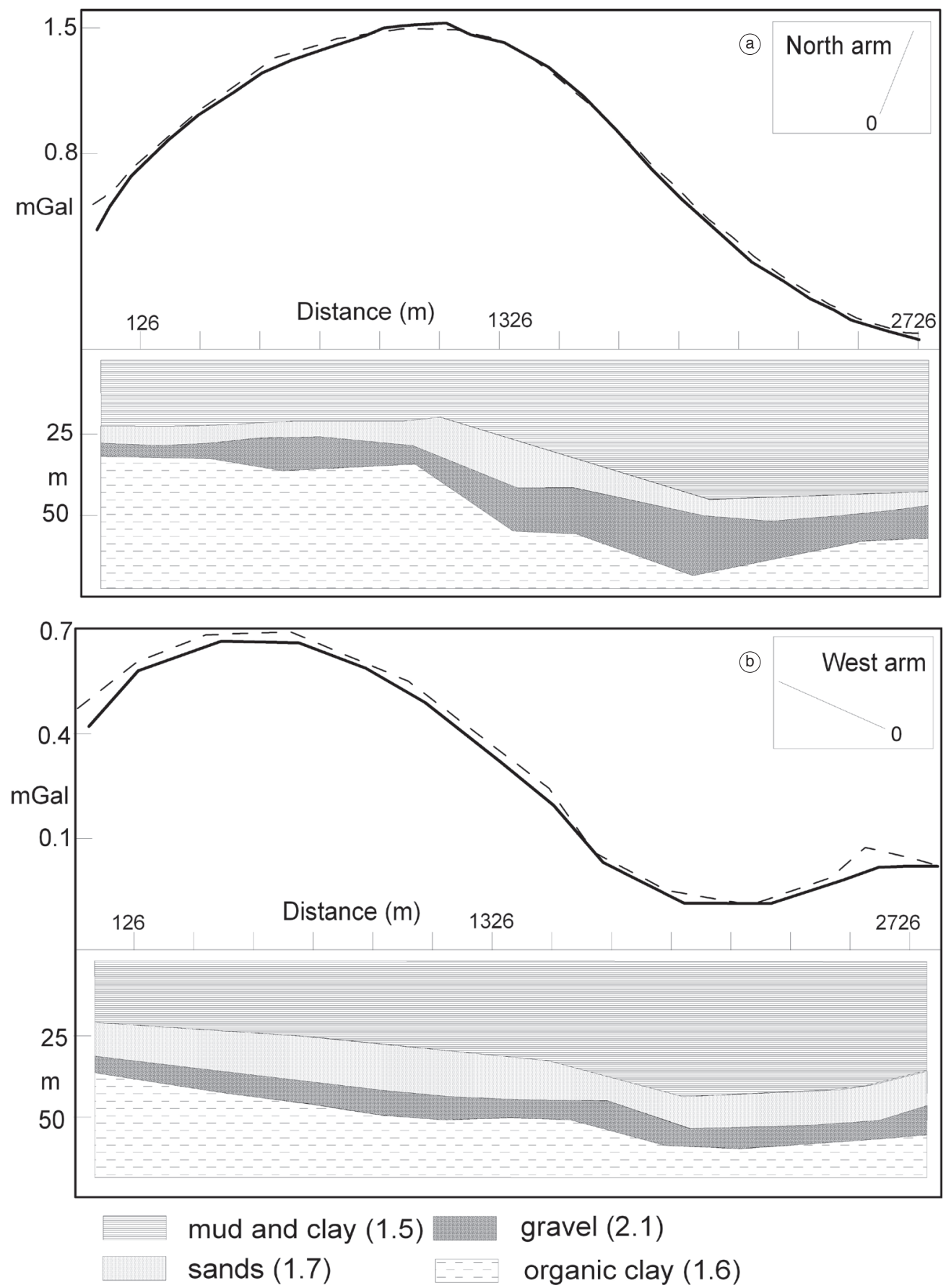

Fig. 5a,b. 2.5D (2.0 Km) gravity model along the North arm (a) and West arm (b) of the VIRGO antenna. The density are in $\mathrm{g} / \mathrm{cm}^{3}$. The dashed line is the observed gravity (mGal). 


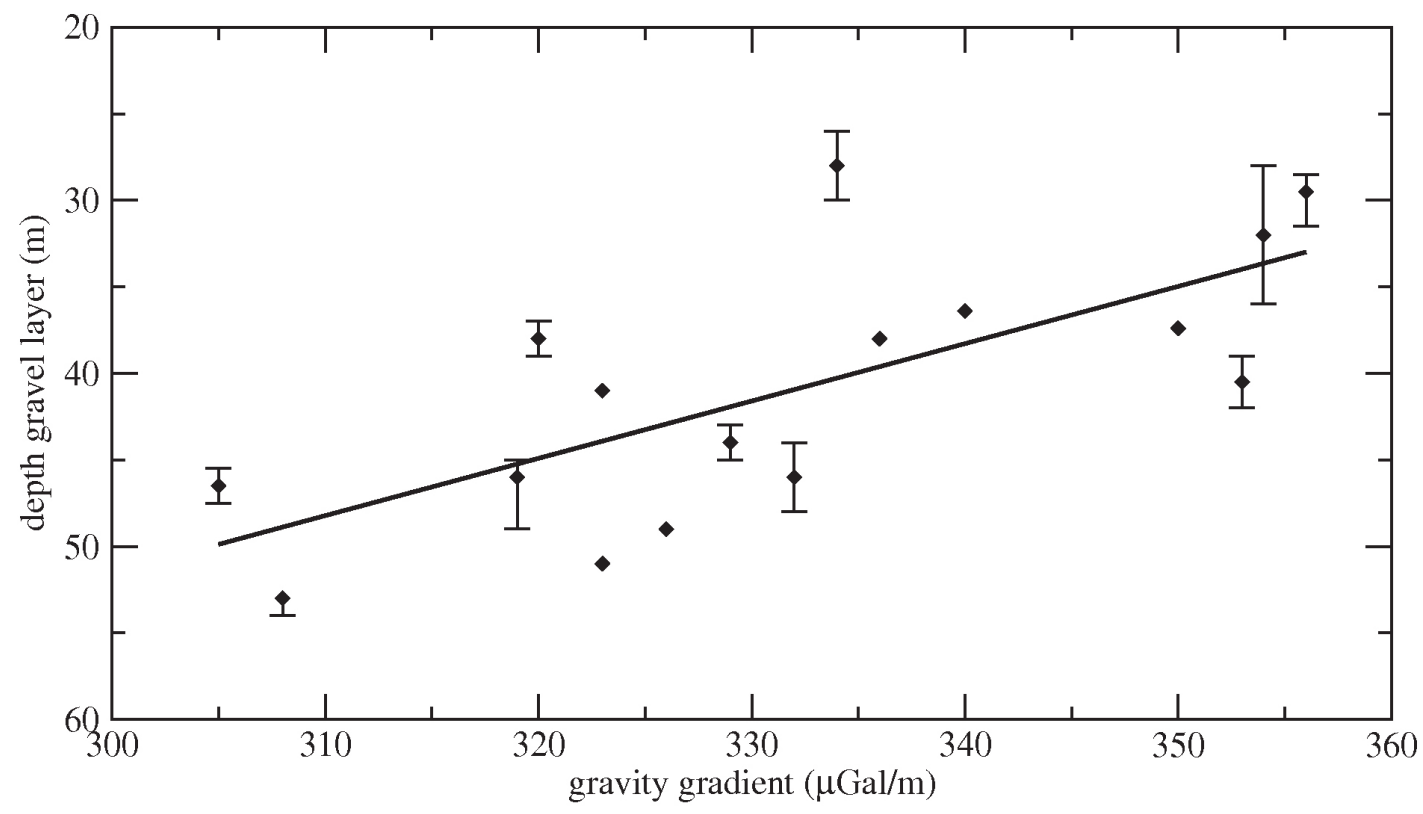

Fig. 6. Plot point and regression line for the gravity gradient data vs depth of gravel layer along the arms of the antenna. The equation of the line is $\mathrm{Y}=-0.33 \mathrm{X}+150.9$ (slope standard deviation is $0.089 \mathrm{~m}^{2} / \mu \mathrm{Gal}$ ), $\mathrm{X}$ axis represents the gravity gradient, $\mathrm{Y}$ axis represents the depth of the gravel layer.

was useful to estimate the depth position of the gravel surface where no data are measured. The result of this processing was plotted in a 3D map (fig. 7). This model shows a main negative anomaly pattern trending NNE-SSW with values that decrease southward; this morphology seems probably connected to a palaeo-alluvial system of the Serchio from the Bientina River. This pattern matches well the geometry of the fault system. In the late Pleistocene, the NE-SW main fault system was active in the Pisa plain (Cantini et al., 2001) with an uplift of the Pisa Mountains; this tectonic trend was probably still active also during the Holocene time.

The conglomeratic succession deposited during the floods event is eroded by successive phases related to the decreasing of the sea level. This is in agreement with the presence of the small thickness of the gravel corresponding with the depositional zone.

The investigation of the exact path of the depression area was not possible, due to the lack of gravity stations in the northern sector of the study area.

\section{Conclusions}

The detailed structural model of the near subsurface of VIRGO (Pisa plain, Italy) is obtained by a new MVG survey. The density values of the main shallow deposits, $2.1 \mathrm{~g} / \mathrm{cm}^{3}$ for the conglomeratic deposits, $1.7 \mathrm{~g} / \mathrm{cm}^{3}$ for the sands and $1.5 \mathrm{~g} / \mathrm{cm}^{3}$ for the mud-clay successions were deduced from a 2.5D gravity modeling along the arms of the antenna. The gravity gradient values acquired during the survey were interpreted using geological information derived from geotechnical drilling, to provide a $3 \mathrm{D}$ distribution of the gravel-conglomerates interface at the VIRGO site. In this 3D frame the negative anomaly trending NNE-SSW clearly shown by the gradient model can be interpreted as a palaeo-alluvial system of the Pisa plain. Among the two arms of the antenna (cen- 


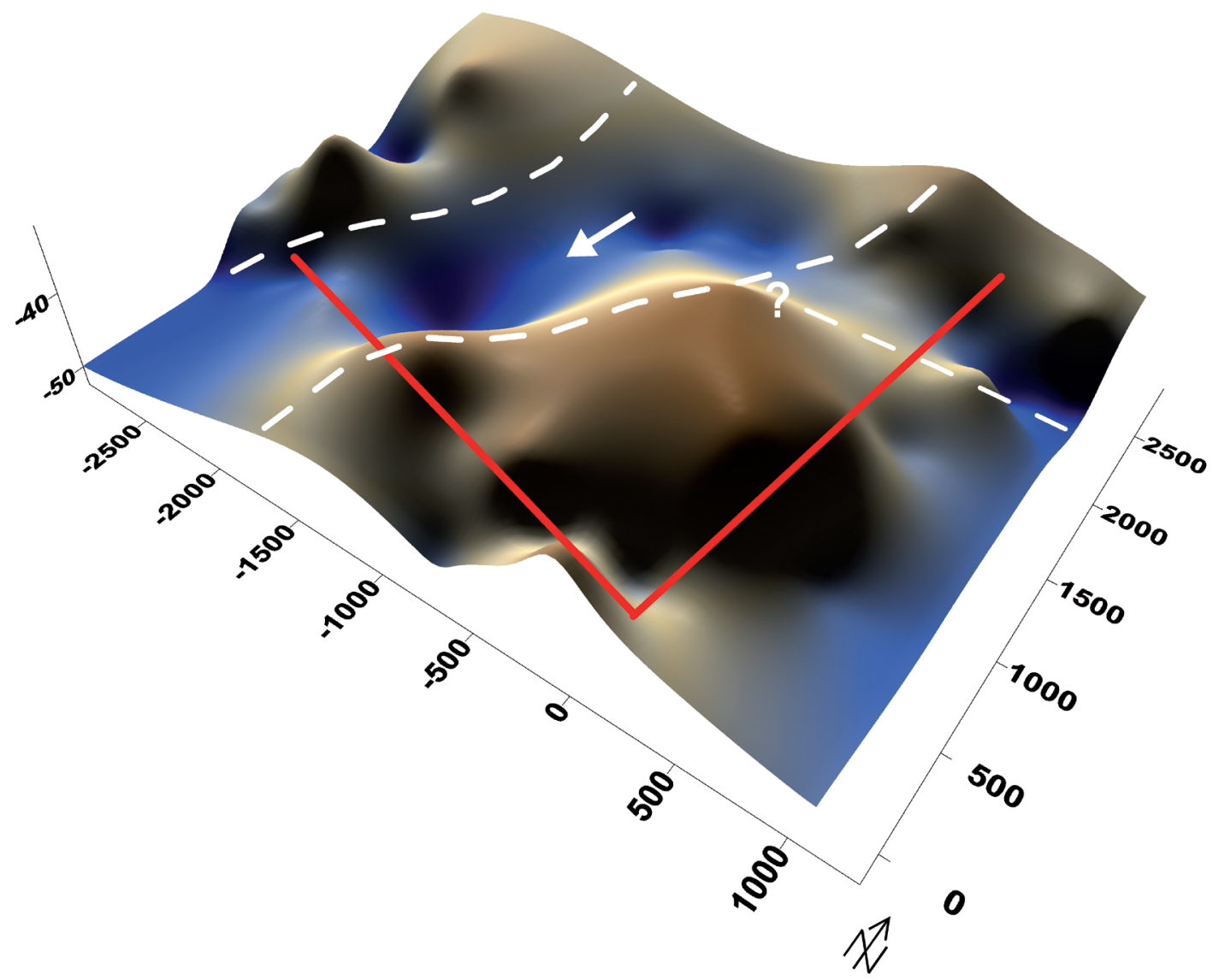

Fig. 7. Gradient gravity model of the gravel surface. The red lines represent the two orthogonal arms of the VIRGO antenna. The dashed white lines are the boundaries of the palaeo-alluvial path.

tre of the survey area), the gravel layer is deepened to a maximum depth of $50 \mathrm{~m}$ below the topographic level.

An improvement to the model could be obtained by extending the survey area for better evaluation of the trend of geological layers, particularly in the northern sector, where the negative pattern is not completely investigated.

The present work shows that the MVG measurements performed with high accuracy instrumentation can serve as a rapid and non-invasive tool useful for estimating the anomaly of the earth's gravitational field directly caused by shallow buried bodies, especially in regions characterized by a low topographic gradient.

\section{Acknowledgements}

This work was supported by the Consorzio Universitario della Spezia and by MIUR grant MM02248142 «Newtonian Noise in Gravitational Wave Detectors».

We thank Peter Vajda for his careful revision of the manuscript.

\section{REFERENCES}

Ager, C. A., and J. O. LiARD (1982): Vertical gravity gradient surveys: field results and interpretation in British Columbia, Canada, Geophysics, 47, 919-925.

Bartole, R., L. Torelli, G. Mattei, D. Peis and G. Bran- 
COLINI (1991): Assetto stratigrafico-strutturale del Tirreno Settentrionale: stato dell'arte, Studi Geologici Camerti, 1, 115-140.

ButLER, D. K. (1984): Microgravimetric and gravity gradient techniques for detection of subsurface cavities, Geophysics, 49, 1084-1096.

Cantini, P., G. Testa, G. Zanchetta and R. Cavallini (2001): The Plio-Pleistocene evolution of extensional tectonics in northern Tuscany, as constrained by new gravimetric data from the Montecarlo Basin (lower Arno Valley, Italy), Tectonophysics, 330, 2543.

Carmignani, L,. F.A. Decandia, P.L. Fantozzi, A. LazZARETTO, D. LotTA and M. MECCHERI (1994): Tertiary extensional tectonics in Tuscany (northern Apennines Italy), Tectonophysics, 238, 295-315.

CARon, B., et al. (VIRGo Collaboration) (1997): The Virgo interferometer, Class. Quantum Grav., 14, 1461-1469.

FAJKLEWICZ, Z.I. (1976): Gravity vertical gradient measurements for the detection of small geologic and anthropogenic forms, Geophysics, 41, 1016-1030.

FANUCCI, F., M. FIRPO and M. RAMELla (1987): Genesi ed evoluzione di piane costiere del Mediterraneo: esempi di piccole piane della Liguria, Geogr. Fis. Dinam. Quat., 10, 193-203.

Hammer, S. and R. Anzoleaga (1975): Exploring for stratigraphic traps with gravity gradients, Geophysics, 40, 256-268.

Hunt, T., M. Sugihara, S. Tatsuya and T. Takemura (2002): Measurements and use of the vertical gravity gradient in correcting repeat microgravity measurement for the effects of ground subsidence in geothermal systems, Geothermics, 31, 525-543.

Kumagai, N., E. ABE and Y. Yoshimura (1960): Measurements of the vertical gradient of gravity and its significance, Boll. Geof. Teor \& Appl., 8, 607-630.

Marson, I., and E.E. Klingele (1993): Advantages of using the vertical gradient of gravity for 3-D interpretation, Geophysics, 58, 1588-1595.

Patacca, E., R. SARTori and P. Scandone (1990): Tyrrhenian basin and Apenninic arcs: kinematic relations since late-Tortonian times, Mem. Soc. Geol. It., 45, 425-451.

Telford, W.M., L.P. Geldart and R.E. SherifF (1990): Applied Geophysics, 2nd ed. (Cambrige University Press, New-York), 10-60.

Thyssen-Bornemisza, S. and W.F. STACKLER (1956): Observation of the vertical gradient of gravity in the field, Geophysics, 21, 771-779.

(received June 11, 2008; accepted October 21, 2008) 